\title{
Characterization of inflammatory cell infiltrate of scleroderma skin: B cells and skin score progression
}

Silvia Bosello ${ }^{1,2 \dagger}$, Cristiana Angelucci ${ }^{3 \dagger}$, Gina Lama ${ }^{3}$, Stefano Alivernini ${ }^{1,2}$, Gabriella Proietti ${ }^{3}$, Barbara Tolusso ${ }^{1,2}$, Gigliola Sica ${ }^{3}$, Elisa Gremese ${ }^{1,2}$ and Gianfranco Ferraccioli ${ }^{1,2^{*}}$

\begin{abstract}
Background: The purpose of this study was to investigate the frequency and the distribution of inflammatory cell infiltrate in two sets of cutaneous biopsies derived from clinically affected and unaffected skin in patients with systemic sclerosis (SSc) and to test correlation between the cell infiltrate and the progression of skin involvement.

Methods: Skin was immunohistochemically assessed to identify CD68, CD3, CD20 and CD138-positive (+) cells in clinically affected and unaffected skin in 28 patients with SSc. Patients were followed for 6 months and the characteristics of the infiltrate were analyzed according to disease duration, clinical features and skin involvement progression.

Results: In all SSc cutaneous specimens, cellular infiltrates were found in a perivascular location predominantly in the mid and deeper portions of the dermis. All the analyzed biopsies showed a $\mathrm{CD}^{+}$and $\mathrm{CD} 8^{+}$cell infiltrate and the mean number of $\mathrm{CD}^{+}$and of $\mathrm{CD} 8^{+}$cells was higher in clinically involved skin $\left(\mathrm{CD}^{+}, 71.7 \pm 34.6\right.$ and $\mathrm{CD}^{+} 8^{+}, 26.3 \pm 8.4$, respectively) than in clinically uninvolved skin $\left(\mathrm{CD}^{+}, 45.7 \pm 36.0\right.$ and $\mathrm{CD} 68^{+}, 13.6 \pm 6.1$, respectively) ( $p<0.001$ for both comparisons). $\mathrm{CD}^{+} 0^{+}$cells were found in 17 (60.7\%) patients and in these patients the mean number of $\mathrm{CD}_{20}{ }^{+}$cells was higher in clinically involved (4.7 \pm 5.9$)$ than in uninvolved skin (1.9 \pm 2.9$)$, $(p=0.04)$. There was a greater number of $\mathrm{CD}_{2} \mathrm{O}^{+}$cells in patients with early SSc compared with patients with long-standing disease. CD138 ${ }^{+}$cells were found in 100\% of biopsies of clinically involved skin and in $89.3 \%$ of biopsies of uninvolved skin. The mean number of $\mathrm{CD} 138^{+}$cells was higher in clinically involved skin (3.6 \pm 2.3$)$ than in clinically uninvolved skin $(1.9 \pm 1.7),(p<0.001)$. Seven patients experienced more than $20 \%$ worsening in the skin score after 6 months of follow up; all of them had a $\mathrm{CD}_{20}{ }^{+}$skin infiltrate on biopsy of clinically involved skin.
\end{abstract}

Conclusions: Our results confirm that mononuclear cells are present in the skin of all patients with SSc, underlining the role of inflammatory cell infiltrates in skin involvement in SSc. B cells in the skin seem to characterize patients with early diffuse skin disease and to correlate with skin progression.

Keywords: Systemic sclerosis, T cells, B cells, Macrophages, Skin involvement

\footnotetext{
* Correspondence: gianfranco.ferraccioli@unicatt.it; gff1990@gmail.com

${ }^{\dagger}$ Equal contributors

'Unità Operativa Complessa di Reumatologia, Istituto di Reumatologia e

Scienze Affini, Università Cattolica del Sacro Cuore, Rome, Italy

${ }^{2}$ Fondazione Policlinico Universitario Agostino Gemelli, Via G. Moscati,

31-00168 Rome, Italy

Full list of author information is available at the end of the article
} 


\section{Background}

Progressive systemic sclerosis (SSc) or scleroderma is a chronic connective tissue disorder characterized by vascular and cellular abnormalities that predominate in the early stages of disease and eventually lead to extensive cutaneous and visceral fibrosis, which is most prominent in the later stages [1-3]. The pathologic phenotype of the disease is complex and, consequently, its etiology and the effective therapies to prevent its progression remain elusive.

Cutaneous mononuclear cells are a frequent histopathological finding in SSc. Previous studies have recorded an increase in the number of mast cells [4, 5], macrophages [3, 6-11] and T lymphocytes [3, 6, 8-12], in particular in the early stages of SSc. Furthermore, microarray analysis in the lungs and in the skin of patients with scleroderma indicates overexpression of macrophage marker genes [13-16]. In vitro studies have demonstrated that all these cells can produce several cytokines and stimulate fibroblasts [1].

To date, although there have been various reports of studies of the B cell infiltrate in SSc [3, 6, 8-10, 13, 17-19], its characterization in skin affected by scleroderma is still incomplete. Recently, some encouraging results suggested a possible use of an anti-CD20 monoclonal antibody (rituximab) for the treatment of early, progressive and diffuse scleroderma, suggesting a role for B cells in the pathogenesis of the disease in the early stage [17-23]. In fact, it has been shown that patients with SSc present with autoantibody production [24], hyper- $\gamma$-globulinemia, polyclonal B cell hyperactivity [25] and abnormalities in the B cell compartments, characterized by an increase in naïve cells and a decrease in activated memory B cells [26]. In addition, in scleroderma there is markedly increased expression of CD19, a signal transduction molecule of B cells that regulates production of autoantibodies, in both memory and naïve B cells $[26,27]$. In patients with diffuse SSc (dSSc), analysis of DNA microarrays of cutaneous biopsies have demonstrated higher expression of clusters of genes of $\mathrm{CD}^{2} 0^{+}$cells and of plasma cells [13].

In an attempt to further clarify the characteristics of the cellular infiltrate, and mostly the possible role of $B$ cells in skin fibrosis, we investigated the frequency and the distribution of mononuclear cells in two sets of cutaneous biopsies derived from clinically affected and unaffected skin from patients with SSc. The characteristics of the infiltrate were also analyzed according to disease duration, clinical features of the patients and skin score modification after 6 months.

\section{Methods}

\section{Patients}

Patients with SSc ( $\mathrm{n}=28$ (24 female and 4 male) ) attending the outpatient clinic of the Division of Rheumatology of our institution agreed to undergo skin biopsies on both clinically affected and unaffected skin and were included in the study. All patients fulfilled the old and the new classification criteria for scleroderma proposed by the European League Against Rheumatism (EULAR) and the American College of Rheumatology (ACR) [28, 29]. Informed signed consent to undergo biopsies and to provide skin samples and clinical data for research purposes was provided by all the patients. This research has been performed in accordance with the Declaration of Helsinki and it was approved by our institutional ethics committee (Comitato Etico Università Cattolica del Sacro Cuore 1883/12).

Demographic and clinical characteristics were collected in all patients with SSc enrolled in the study. Patients were grouped according to the classification proposed by LeRoy in patients with limited SSc (ISSc) or diffuse SSc (dSSc) [30]. The extent of skin involvement was evaluated by the Rodnan skin score, performed by two assessors (always the same at every evaluation) whose results were averaged [31], at the time of skin biopsy and after a mean follow-up time of $6.5 \pm 0.8$ months. A modification of skin score higher than $20 \%$ was considered clinically significant progression [32, 33]. Antinuclear antibodies (ANA) were determined by indirect immunofluorescence using Hep-2 cells as substrates and autoantibody specificities were further assessed by ELISA (Shield, Dundee, UK).

Cutaneous specimens were taken from patients with $\mathrm{SSc}$, by surgical excision with a 6-mm punch from the distal forearm for the clinically involved skin (skin score $>1$ at this site) and from the buttock for clinically uninvolved skin (skin score $=0$ at this site). The presence of mononuclear inflammatory cells was investigated in all skin specimens, in particular CD3 as a marker of T lymphocytes, CD20 as a marker of B-lymphocytes (local mature B cells and memory B cells), CD138 as a marker of plasma cells and CD68 as a marker of residential macrophages.

At the time of the skin biopsies, the activity index [34] and the severity index [35] were assessed and Global Health $(\mathrm{GH})$ status and Health Assessment Questionnaires (HAQ) were administered to patients to evaluate the influence of the disease on daily functions.

All 28 patients continued to receive iloprost (an infusion of $0.5-2 \mathrm{ng} / \mathrm{kg}$ body weight/min for 5 days every 2 months), calcium channel blockers (nifedipine 20-40 $\mathrm{mg} /$ day) and acetylsalicylic-acid from the moment of diagnosis. Patients receiving corticosteroids or immunosuppressive drugs at the time of skin biopsy were excluded from the study. During the follow-up period, 12 patients were treated with anti-CD20 monoclonal antibody (rituximab) with or without cyclophosphamide for skin disease progression and/or lung involvement, while the other 16 patients did not receive immunosuppressive drugs. 
Internal organ involvement was evaluated no longer than one month before or after the skin biopsies. All patients with SSc underwent pulmonary function tests (PFTs) to define forced vital capacity (FVC) and diffusing capacity for carbon monoxide (DLCO), and high resolution computed tomography (HRCT) was performed to assess lung involvement [36]. Renal involvement was defined as a scleroderma crisis or as the presence of proteinuria or elevation in creatinine serum level. Electrocardiography (ECG) and echocardiography were also performed in all patients: cardiac involvement was defined as the presence of conduction disturbance, left ventricular ejection fraction (LVEF) and $<50 \%$, pulmonary artery systolic pressure (PASP) $>35 \mathrm{mmHg}$ on echocardiography. Gastro-intestinal involvement was defined as the presence of gastroesophageal reflux symptoms or the evidence of gastrointestinal motility disturbance.

Four female healthy subjects (age range 36-55 years) gave their informed consent to undergo forearm skin biopsy, as controls.

\section{Immunohistochemical analysis}

Immunohistochemical analysis was carried out on 5- $\mu \mathrm{m}$ thick tissue sections on polylysine-coated slides. After deparaffinization and rehydration, antigen retrieval was performed. Slide-mounted sections were heated in a microwave oven at 700 watt two times for $4 \mathrm{~min}$ in 10 $\mathrm{mmol} / \mathrm{L}$ sodium citrate buffer $(\mathrm{pH}$ 6.0). Quenching of endogenous peroxidase activity was performed with Tris-buffered saline (TBS) ( $\mathrm{pH}$ 7.6) containing $2 \%$ hydrogen peroxide $\left(\mathrm{H}_{2} \mathrm{O}_{2}\right)$ for $10 \mathrm{~min}$ at room temperature (RT). To prevent non-specific binding, blocking was performed with Super block (UCS Diagnostics, Rome, Italy) for $8 \mathrm{~min}$ at RT. Sections were incubated with anti-CD3 mouse monoclonal antibodies (mAb) (1:50 dilution; Clone PS1, Abcam, Cambridge, MA, USA) or anti-CD20 mouse mAb (1:100 dilution; Clone L26; Novus Biologicals, Littleton, CO, USA) or human anti-CD138 (Syndecan-1) rabbit polyclonal antibodies (Ab) (1:25 dilution; Spring Bioscience, CA, USA). Tissues were then incubated with the Super Picture HRP Polymer Conjugated Broad Spectrum (Invitrogen, Carlsbad, CA, USA) for $30 \mathrm{~min}$ at RT and the chromogenic reaction was developed with $3,3^{\prime}$-diaminobenzidine tetrahydrochloride solution (Zymed Laboratories, South San Francisco, CA, USA). The nuclei were lightly counterstained with hematoxylin. Negative controls without primary Abs were performed for all reactions. Human tonsil specimens were used as positive controls. CD68 was immunohistochemically assessed using an autostainer (BOND MAX III, Leica Biosystems, Newcastle, UK), according to the manufacturer's standard protocol, using an anti-CD68 mouse anti-human mAb (ready to use; clone 514H12, Leica Biosystems) [37].
Cellular infiltrates were studied in the dermis and/ or subcutaneous tissue and were classified as either perivascular or diffuse. Positive cells were counted by two independent observers in a total of six randomly selected fields (total area $7.38 \mathrm{~mm}^{2}$ ) for each section at $\times 400$ magnification, under a light microscope (Axioskop 2 plus, Zeiss). The total number of positive cells was calculated and reported as mean $\pm \mathrm{SD}$, median and range.

\section{Statistical analysis}

All analyses were carried out using SPSS 15.0 (Chicago, IL, USA). Categorical variables were expressed as numbers, and quantitative variables as mean \pm SD if normally distributed, and as median plus range if not. Categorical variables were analyzed using the chi-square $\left(\mathrm{X}^{2}\right)$ test or Fisher's test, depending on sample size restrictions. Nonnormally distributed continuous data were compared using the Mann-Whitney test and the Wilcoxon test (for paired data). A value of $p<0.05$ was considered statistically significant. Correlation was tested using Spearman's rank order correlation for non-normally distributed interval data.

\section{Results}

Demographic, clinical and immunological characteristics of enrolled patients with SSc

Demographic and clinical characteristics of patients with SSc enrolled in the study are shown in Table 1.

The mean age $( \pm$ SD) of the patients with SSc was $44.6 \pm$ 15.4 years and the median disease duration was 16.0 (range 3.0-360.0) months. There were 19 patients (67.9\%) with early disease, defined as diagnosis up to 3 years after the occurrence of Raynaud's phenomenon; the remaining 9 patients $(32.1 \%)$ had long-standing disease. There were 20 patients $(71.4 \%)$ with dSSc. The baseline mean modified Rodnan skin score was $15.8 \pm 11.3$ (range 2.0-43.0). Antitopoisomerase antibodies (anti-Scl-70 Abs) were present in $21(75.0 \%)$ patients and anti-centromere Abs (ACA) in 3 patients $(10.7 \%)$. One patient presented with RNA polymerase III autoantibody positivity; the other three patients were ANA positive only (one with a nucleolar pattern and two with a homogeneous pattern) (Additional file 1: Table S1).

\section{Skin $\mathrm{CD} 20^{+}$B-cells and CD $138^{+}$plasma cell infiltrates characterize patients with SSc based on disease duration and subset}

In all 56 cutaneous specimens from patients with SSc, mononuclear cell infiltrates were found in a perivascular location, predominantly in the mid and deeper portions of the dermis. CD20 ${ }^{+}$cells were found in 17 (60.7\%) out of the 28 patients with SSc: 9 of these patients $(52.9 \%)$ had $\mathrm{CD}_{20}^{+}$cells in either clinically involved or uninvolved skin, 7 (41.2\%) had $\mathrm{CD}^{2} 0^{+}$cells only in the 
Table 1 Demographic and clinical characteristics of patients with SSc enrolled in the study

\begin{tabular}{|c|c|}
\hline Characteristic & Value \\
\hline Age (years), mean (SD) & $44.6(15.4)$ \\
\hline Age (years), median (range) & $46.0(20.0-67.0)$ \\
\hline Female, number (\%) & $24(85.7)$ \\
\hline Male, number (\%) & $4(14.3)$ \\
\hline Disease duration (months), mean (SD) & $44.7(71.5)$ \\
\hline Disease duration (months), median (range) & $16.00(3-360)$ \\
\hline Early disease, number (\%) & $19(67.9)$ \\
\hline Long-standing disease, number (\%) & $9(32.1)$ \\
\hline Anti-Scl-70 positivity, number (\%) & $21(75.0)$ \\
\hline ACA positivity, number (\%) & $3(10.7)$ \\
\hline RNA polymerase III positivity, number (\%) & $1(3.6)$ \\
\hline ANA positivity ${ }^{a}$, number (\%) & $3(10.7)$ \\
\hline dSSc, number (\%) & $20(71.4)$ \\
\hline ISSc, number (\%) & $8(28.6)$ \\
\hline Skin score, mean (SD) & $15.8(11.3)$ \\
\hline Skin score, median (range) & $14.0(2.0-43.0)$ \\
\hline Activity index, mean (SD) & $4.4(2.0)$ \\
\hline Activity index, median (range) & $4.2(1.0-8.5)$ \\
\hline Severity index, mean (SD) & $8.0(2.6)$ \\
\hline Severity index, median (range) & $7.5(4.0-14.0)$ \\
\hline FVC (\%), mean (SD) & $87.8 \pm 22.1$ \\
\hline FVC (\%), median (range) & $94.0(41.0-123.0)$ \\
\hline DLCO (\%), mean (SD) & $57.3 \pm 18.4$ \\
\hline DLCO (\%), median (range) & $57.0(26.0-93.0)$ \\
\hline HRCT interstitial score, mean (SD) & $7.6(2.3)$ \\
\hline HRCT interstitial score, median (range) & $7.0(4.0-14.0)$ \\
\hline HRCT alveolar score, mean (SD) & $6.7(5.0)$ \\
\hline HRCT alveolar score, median (range) & $6.0(0.0-16)$ \\
\hline ESR, mm/h, mean (SD) & $20.4(20.3)$ \\
\hline ESR, median (range) & $12.0(2.0-84.0)$ \\
\hline
\end{tabular}

The values are indicated as the mean (SD) and median (range) or number (percentage)

ANA antinuclear antibodies, ACA anticentromere antibodies, anti-SCI-70 antitopoisomerase antibodies, $d S S C$ diffuse skin disease, ISSC limited skin disease, FVC forced vital capacity, DLCO diffusion lung carbon monoxide, ESR erythrocyte sedimentation rate

aNA positivity: two patients who were ANA-positive presented with a homogeneous pattern, and one patient presented with a nucleolar pattern

involved skin and one patient with diffuse skin disease and anti-Scl-70 Abs had $\mathrm{CD} 20^{+}$cells only in clinically uninvolved skin. Importantly no $\mathrm{CD} 20^{+}$cells were found in biopsy specimens from healthy volunteers.

In the subgroup that had $\mathrm{CD}^{2} 0^{+}$staining, the mean number of $\mathrm{CD}^{2} 0^{+}$cells was higher in involved $(4.7 \pm 5.9)$ than in uninvolved skin $(1.9 \pm 2.9)$, $(p=0.04$, Table 2$)$. Among the 17 patients with $\mathrm{CD}^{2} 0^{+}$cells on skin biopsy,
12 patients (70.6\%) had early disease, 14 (82.3\%) had diffuse skin involvement and $12(70.6 \%)$ had anti-Scl$70 \mathrm{Ab}$ positivity. Patients with early SSc had higher numbers of $\mathrm{CD}^{+} 0^{+}$cells $(6.3 \pm 6.5)$ than patients with long-standing disease $(1.2 \pm 0.9,(p=0.009))$ in involved skin. In clinically involved skin, patients with dSSc had numbers of $\mathrm{CD}^{2} \mathrm{O}^{+}$cells $(4.9 \pm 6.4)$ comparable to patients with ISSc $(4.3 \pm 4.0)$, but interestingly all patients with $\mathrm{CD} 20^{+}$cells in the clinically uninvolved skin had diffuse disease (Fig. 1).

All patients with B cells in clinically uninvolved skin had anti-Scl-70 Abs, RNA polymerase III autoantibody positivity or ANA positivity; none of the patients with ACA positivity had a B cell aggregate in uninvolved skin.

The 17 patients with $\mathrm{CD} 20^{+}$cells in their skin had shorter disease duration (33.2 \pm 36.8 months), compared to patients without B cell aggregate in skin biopsies (61. $9 \pm 104.6$ months), but this difference was not statistically significant, and there was no significant correlation between the number of $\mathrm{CD}^{2} 0^{+}$cells and disease duration. No association emerged between the presence of $\mathrm{CD}_{20}{ }^{+}$cells and restrictive lung involvement or heart or gastrointestinal disease.

The number of $\mathrm{CD}_{2} \mathrm{O}^{+}$cells in involved skin cells directly correlated with the number of $\mathrm{CD} 20^{+}$cells in uninvolved skin $(r=0.62, p<0.001)$ and with the number of $\mathrm{CD}^{+}$cells in involved skin $(r=0.4, p=0.03)$. Furthermore, $\mathrm{CD} 20^{+}$cells in involved skin were inversely correlated with DLCO values $(r=-0.5, p=0.01)$ and with FVC values $(r=-0.5, p=0.003)$.

CD138 ${ }^{+}$cells were found in $100 \%$ of involved skin biopsies and in $89.3 \%$ of clinically uninvolved skin samples (Table 2), but none of the healthy controls had plasma cells in the skin.

The mean number of $\mathrm{CD} 138^{+}$cells was higher in clinically involved skin $(3.6 \pm 2.3)$ than in uninvolved skin $(1.9 \pm 1.7(p<0.001))$ (Fig. 2). Although in patients with early disease the number of $\mathrm{CD} 138^{+}$cells in involved skin $(4.2 \pm 2.6)$ and in uninvolved skin $(2.1 \pm 1.9)$ was higher than in longstanding disease (involved skin $2.6 \pm 1.4$, uninvolved skin $1.7 \pm 1.1$ ), this difference was not statistically significant. Furthermore, no statistically significant difference was found in the mean number of $\mathrm{CD} 138^{+}$in patients with diffuse skin disease either in involved $(4.1 \pm 2.6)$ or uninvolved $(2.1 \pm 1.9)$ skin compared to patients with ISSc (involved skin $2.5 \pm 1.0$, uninvolved skin $1.7 \pm 1.0$ ). No differences were observed in plasma cell infiltrates in patients with different autoantibodies specificities or in patients with different organ involvement.

In involved skin, the number of $\mathrm{CD}_{138^{+}}$cells directly correlated with the number of CD20 $0^{+}$cells $(r=0.6, p=0.01)$ and with the number of $\mathrm{CD}^{+}$cells $(r=0.5, p=0.01)$, whereas there was no significant correlation on analysis of the non-affected skin samples. 
Table $2 \mathrm{CD}^{2} 8^{+}, \mathrm{CD}^{+}, \mathrm{CD} 20^{+}$and $\mathrm{CD}_{138^{+}}$cell counts on paired skin specimens in the 28 patients with SSC

\begin{tabular}{llll}
\hline & Clinically involved skin & Clinically uninvolved skin & $P$ \\
\hline $\mathrm{CD}^{+} 8^{+}$mean (SD) & $26.3(8.3)^{\mathrm{a}}$ & $13.6(6.1)^{\mathrm{a}}$ & $12.5(3.0-25.0)$ \\
$\mathrm{CD}^{+}$median (range) & $24.5(12.0-40.0)$ & $45.7(36.0)^{\mathrm{a}}$ & 0.001 \\
$\mathrm{CD}^{+}$mean (SD) & $71.7(34.6)^{\mathrm{a}}$ & $29.8(1.0-130.0)$ \\
$\mathrm{CD}^{+}$median (range) & $70.0(7.0-146.0)$ & $1.9(2.9)^{\mathrm{b}}$ \\
$\mathrm{CD} 20^{+}$mean (SD) & $4.7(5.9)^{\mathrm{b}}$ & $1.0(0.0-11.5)$ \\
$\mathrm{CD} 20^{+}$median (range) & $2.0(0.0-25.0)$ & $1.9(1.7)^{\mathrm{c}}$ \\
$\mathrm{CD} 138^{+}$mean (SD) & $3.6(2.3)^{\mathrm{a}}$ & $1.5(0.0-9.0)$ \\
$\mathrm{CD} 138^{+}$median (range) & $3.0(0.5-11.5)$ & & 0.04 \\
\hline
\end{tabular}

The values are the mean (SD) and median (range)

${ }^{a}$ Mean (SD) and median (range) of $\mathrm{CD} 8^{+}, \mathrm{CD}^{+}, \mathrm{CD} 138^{+}$in clinically involved skin (forearm) and of $\mathrm{CD} 68^{+}$and $\mathrm{CD} 3^{+}$in clinically uninvolved skin (buttock) refers to the duplicate skin samples from patients

${ }^{\mathrm{b}}$ Mean (SD) and median (range) of $\mathrm{CD}_{20} 0^{+}$was calculated considering only the 17 patients (60.7\%) that had almost one CD20+ cell in clinically involved skin or in clinically uninvolved skin

cMean (SD) and median (range) of $\mathrm{CD}_{138^{+}}$in clinically uninvolved skin was calculated considering 25 out of 28 (89.3\%) patients with CD138 + cells in uninvolved skin specimens

\section{Skin $\mathrm{CD}^{+} \mathrm{T}$-lymphocyte infiltrates are differentially presented in patients with SSC based on the skin compartment and autoantibody positivity}

$\mathrm{CD}^{+}$cells were found in all skin biopsies of both healthy subjects and patients with SSc. In healthy subjects, $\mathrm{CD}^{+}$ cell number was significantly smaller $(8.0 \pm 2.0)$ compared to that in involved $(71.7 \pm 34.6,(p<0.001))$ or uninvolved $(45.7 \pm 36.0,(p<0.001))$ skin from patients with SSc.

The mean number of $\mathrm{CD}^{+}$cells was higher in clinically involved skin than clinically uninvolved skin, $(p=0.001)$ (Table 2, Fig. 3). No statistically significant difference in the mean number of $\mathrm{CD}^{+}$cells was found in skin from patients with early compared to long-standing SSc, either in involved or uninvolved skin (Table 2).

The mean number of $\mathrm{CD}^{+}$cells in involved skin was higher in patients with dSSc $(75.1 \pm 35.8)$ than in patients with 1SSc (63.2 \pm 31.7), but this difference was not statistically significant, probably due to the wide variation in cell numbers.

The number of $\mathrm{CD}^{+}$cells was comparable in involved skin from patients with SSc regardless to anti-Scl-70 Ab positivity. In clinically uninvolved skin biopsies, patients with anti-Scl-70 Abs had a greater number of T lymphocytes (51. $7 \pm 38.7)$ than anti-Scl-70 Ab-negative patients $(27.7 \pm 18.8$, $(p=0.05))$. It is worth mentioning that the small group of patients with ACA positivity had a smaller number of $\mathrm{CD}^{+}$ cells in both affected and unaffected skin. The number of $\mathrm{CD}^{+}$cells in involved skin directly correlated with the number of $\mathrm{CD}^{+}$cells in uninvolved skin $(r=0.5, p=0.009)$ and inversely correlated with DLCO $(r=-0.4, p=0.002)$, but there was no correlation with the Rodnan skin score, disease activity or severity scores.

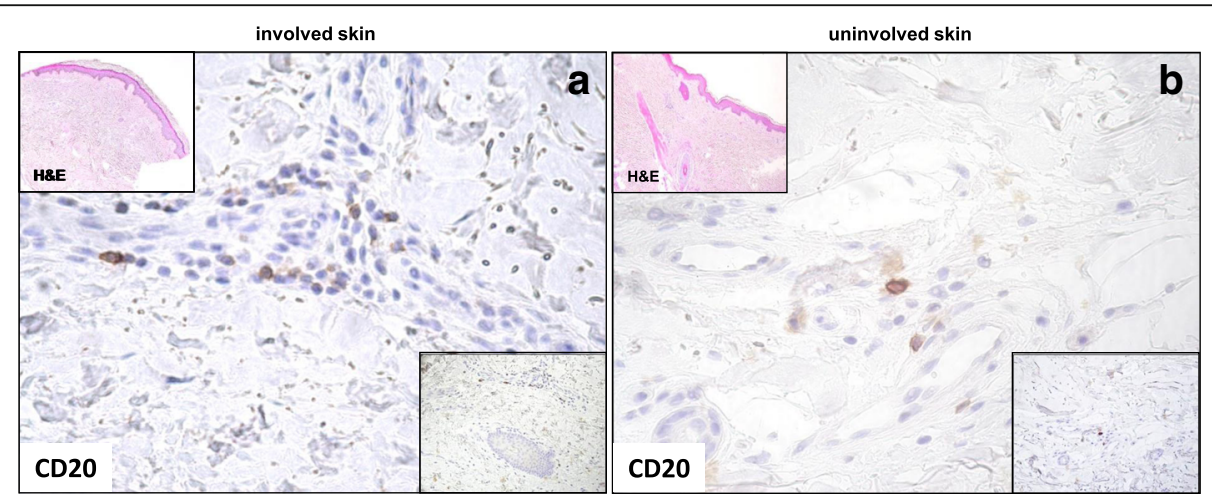

Fig. 1 CD20 cell staining in involved and uninvolved skin from a patient with systemic sclerosis (SSc). a Cellular infiltrate in involved skin (distal forearm biopsy) from a patient with early anti-Scl- $70^{+}$diffuse SSc showing an appreciable number of $\mathrm{CD} 2 \mathrm{O}^{+}$cells in perivascular areas. $\mathbf{b}$ Uninvolved skin (buttock biopsy) from the same patient showing the presence of a smaller number of $\mathrm{CD} 20^{+}$cells around blood vessels. Original magnification $\times 400$ (a and $\mathbf{b})$. Nuclei were counterstained by hematoxylin. Bottom insets show the infiltrating cells at a lower magnification $(x$ $200)$. Insets at the top of the figures show hematoxylin and eosin (H\&E) staining of involved and uninvolved skin $(\times 50)$ 


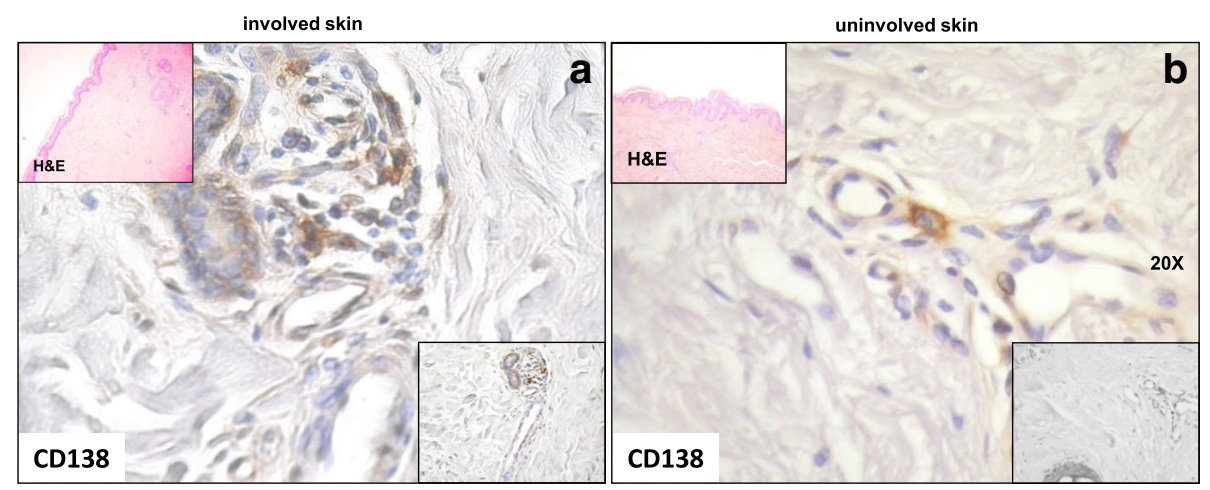

Fig. 2 CD138 cell staining in involved and uninvolved skin from a patient with systemic sclerosis (SSc). a Involved skin (distal forearm biopsy) from a patient with an early anti-SCl-70+ diffuse SSc showing an appreciable number of CD138 ${ }^{+}$cells in perivascular areas. b Uninvolved skin (buttock biopsy) of the same patient showing the presence of a smaller number of CD138 $8^{+}$cells around blood vessels. Original magnification $\times$ 400 (a and $\mathbf{b})$. Nuclei were counterstained by hematoxylin. Bottom insets show the infiltrating cells at a lower magnification $(\times 200)$. Insets at the top of the figures show hematoxylin and eosin (H\&E) staining of involved and uninvolved skin $(\times 50)$

\section{Skin $\mathrm{CD}^{+} 8^{+}$macrophage infiltrates are differentially presented in patients with SSc based on the skin compartment}

Using paired skin samples, $\mathrm{CD}^{+}$cell count was significantly higher in clinically involved $(26.3 \pm 8.3)$ compared to uninvolved skin from patients with SSc (13.6 $\pm 6.1)(p=0.001)$ (Fig. 4), the $\mathrm{CD}^{+} 8^{+}$cells having a preferential perivascular distribution within the dermis.

Grouping patients with SSc according to the disease subset, we found that $\mathrm{CD}^{+} 8^{+}$cell count was significantly higher in clinically uninvolved skin from patients with SSc with a diffuse phenotype $(14.8 \pm 5.8)$ compared to patients with SSc with limited disease $(8.3 \pm 4.7)(p=0.05)$, whereas there was no difference in macrophage infiltrate when comparing involved skin samples from patients with dSSc $(27.2 \pm 7.8)$ to skin samples from patients with ISSc $(22.3 \pm 11.7)(p=0.78)$. The number of $\mathrm{CD}^{+} 8^{+}$cells was comparable in involved skin from patients with SSc despite anti-Scl-70 Ab positivity. In clinically uninvolved skin, patients with anti-Scl-70 Abs had a greater number of $\mathrm{CD}^{+} 8^{+}$cells $(15.0 \pm 5.1)$ than patients with SSc without anti-Scl-70 Abs $(4.0 \pm 1.4)(p=0.02$, Table 2$)$.

\section{Cell infiltrate and skin score progression: the role of B cells}

During follow up 12 patients were treated with rituximab with or without cyclophosphamide because of the progression of skin disease, while 16 patients did not receive any treatments because no progression of skin score was present at the time of biopsy (Table 3). At study entry, patients with SSc had comparable immunohistological findings in terms of CD68, CD3, CD20 and CD138 cells in clinically affected and unaffected skin samples after treatment stratification. However, treated patients had a decrease in skin score during follow up from $21.1 \pm 10.9$ to $11.2 \pm 6.2(p=0.03)$, and all but one

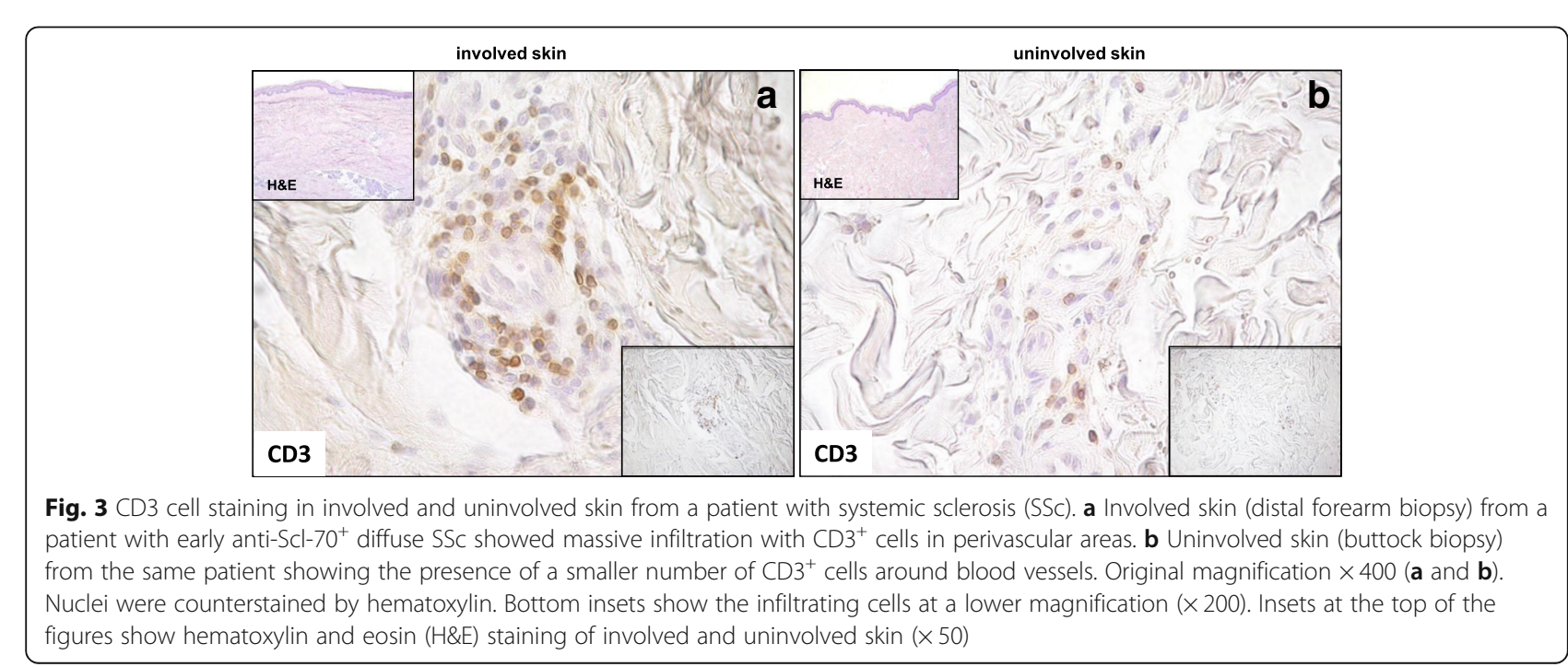



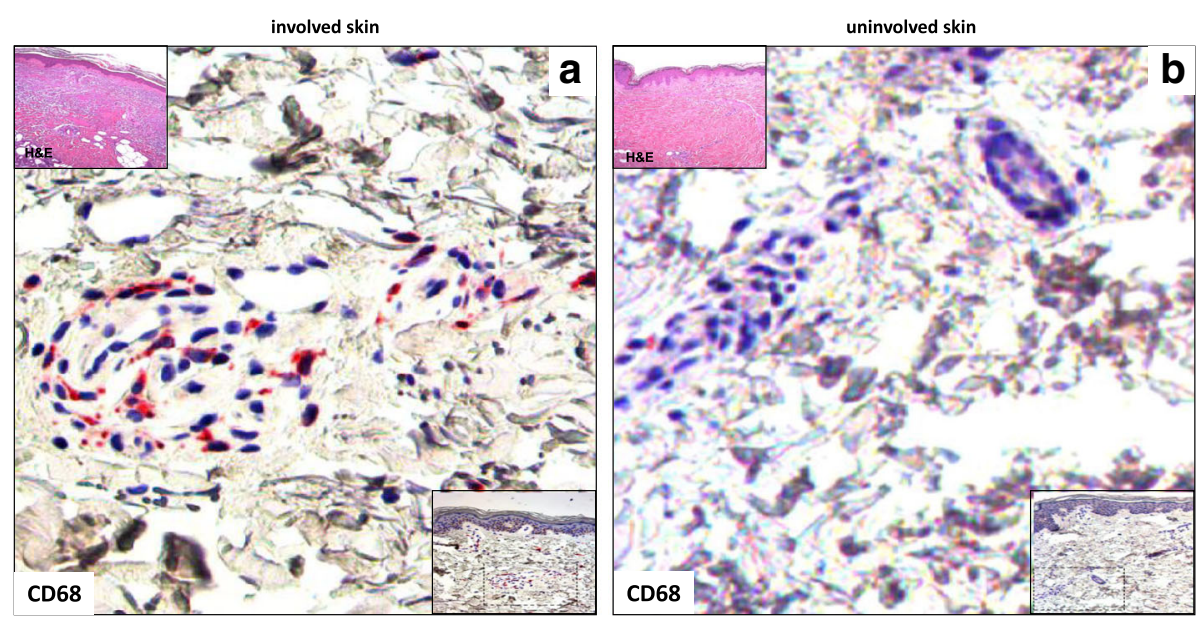

Fig. 4 CD68 cell staining in involved and uninvolved skin from a patient with systemic sclerosis (SSC). a Involved skin (distal forearm biopsy) from a patient with early anti-Scl-70+ diffuse SSC showed an infiltrate of CD68 ${ }^{+}$cells (red) in perivascular areas. $\mathbf{b}$ Uninvolved skin (buttock biopsy) from the same patient showing the presence of a smaller number of $\mathrm{CD} 68^{+}$cells around blood vessels. Original magnification $\times 400$ (a and $\mathbf{b}$ ). Nuclei were counterstained by hematoxylin. Insets at the bottom of the figures show the infiltrating cells at a lower magnification $(\times 200)$. Insets at the top of the figures show hematoxylin and eosin (H\&E) staining of involved and uninvolved skin $(\times 50)$

experienced a response $>20 \%$ in the skin score. The clinical response in term of skin score improvement was not associated with the rate of baseline cell infiltrate.

Among the 16 patients that did not receive immunosuppressive therapy during the follow up, 9 patients had a stable skin score or worsening of the score was less than $20 \%$ after $6.5 \pm 0.8$ months, while 7 patients (43. $7 \%$ ) had more than $20 \%$ worsening of the skin score. The baseline and follow-up skin score in the latter patients were respectively $11.9 \pm 10.6$ and $15.7 \pm 10.3$ $(p=0.02)$. Among the 17 patients with $\mathrm{B}$ cell skin infiltrate at baseline, 8 patients were treated due to progressive skin involvement and 7 untreated patients had worsening during follow up. In the remaining two untreated patients with baseline B cell skin infiltrate, the skin score remained stable during the follow up.

In the 16 untreated patients, 9 patients with scleroderma (56.2\%) had $\mathrm{CD}^{2} 0^{+}$cell skin infiltrate at baseline: 7 of them (77.8\%) experienced worsening of the skin score, while none of the patients without $\mathrm{CD} 20^{+}$cells in the skin specimens experienced worsening of the skin score (Fisher's test, $p=0.03$ ). The mean number of $\mathrm{CD}_{2} \mathrm{O}^{+}$cells in involved skin from the seven patients with worsening of the skin score was higher than that in patients without worsening, but the difference was not statistically significant. Furthermore, the mean number of baseline $\mathrm{CD} 138^{+}$cells in involved skin $(4.6 \pm 3.6)$ and uninvolved $(2.6 \pm 1.1)$ skin biopsies was slightly higher in patients with skin progression compared to patients without skin worsening (involved skin $2.7 \pm 1.1$, uninvolved skin $1.7 \pm 1.3$ ), ( $p$ value not significant).

The mean number of baseline $\mathrm{CD}^{+}$cells in affected and unaffected skin of patients with a worsening of skin score (involved skin $79.3 \pm 48.3$, uninvolved skin $44.8 \pm 37.0$ ) was comparable to the mean number of $\mathrm{CD}^{+}$cells in patients with stable skin score (involved skin $78.6 \pm 20.0$, uninvolved skin $50.3 \pm 31.9)$, ( $p$ value not significant in both comparisons).

Comparable results were obtained for CD68 staining; in fact, the mean number of baseline $\mathrm{CD} 68^{+}$cells in affected and unaffected skin in patients with skin progression (involved skin $31.3 \pm 9.1$, uninvolved skin $10.3 \pm 4.7$ ) was similar to the mean number of $\mathrm{CD}^{+} 8^{+}$cells in patients with a stable skin score (involved skin $24.7 \pm 4.5$, uninvolved skin $14.3 \pm 9.3)$, ( $p$ value not significant in both comparisons).

\section{Discussion}

A cutaneous cellular infiltrate is a frequent histopathologic finding in SSc $[3,6,7,10]$. Cutaneous mononuclear cell infiltrates [3-12] may play a major role in starting and to mediating dermal sclerosis through their effects on fibroblasts [1].

In our study, $\mathrm{T}$ lymphocytes and macrophages were found in all cutaneous specimens from patients with SSc that were analyzed, predominantly in a perivascular location in the mid and/or deeper portion of the dermis. In previous studies, mononuclear cell infiltrates, including macrophages [3, 6-9] and T lymphocytes [3, 6, 8-12], with an increased number also of mast cells $[3,5,6]$, were reported in SSc skin biopsies, above all in the early phases of the disease. In particular, Fleischmajer and coworkers [6] found that only $49 \%$ of patients with SSc had diffuse or perivascular cellular infiltrates in the dermis or subcutaneous tissue; the cells were identified as lymphocytes, plasma cells and macrophages. In this 
Table 3 Clinical and histological characteristics according to immunosuppressive/immunomodulatory treatment and clinical outcome in the 28 patients with SSC

\begin{tabular}{|c|c|c|c|}
\hline & $\begin{array}{l}\text { Immunosuppressive treatment } \\
\text { (12 patients) }\end{array}$ & $\begin{array}{l}\text { No immunosuppressive } \\
\text { treatment ( } 16 \text { patients) }\end{array}$ & $P$ \\
\hline Age (years), mean (SD) & $39.3(13.9)$ & $48.6(16.2)$ & ns \\
\hline Female/male, number & $10 / 2$ & $14 / 2$ & ns \\
\hline Disease duration (months), mean (SD) & $42.8(100.3)$ & $45.8(41.5)$ & ns \\
\hline Early/longstanding disease, number & $10 / 2$ & $9 / 7$ & ns \\
\hline dSSc/ISSc number & $11 / 1$ & $9 / 7$ & 0.05 \\
\hline Skin score baseline, mean (SD) & $21.1(10.9)$ & $11.9(10.6)$ & 0.03 \\
\hline Anti-scl-70 antibodies positivity, number (\%) & 10 & 11 & ns \\
\hline ACA positivity, number & 0 & 3 & \\
\hline ANA positivity, number & 2 & 2 & \\
\hline Presence of $\mathrm{CD}_{20} \mathrm{O}^{+}$cell in skin biopsy, number $(\%)^{\mathrm{a}}$ & $8(66.7)$ & $9(56.3)$ & ns \\
\hline $\mathrm{CD} \mathrm{O}^{+}$in clinically involved skin, mean (SD) & $2.3(3.1)$ & $3.4(6.3)$ & ns \\
\hline $\mathrm{CD} \mathrm{O}^{+}$in clinically uninvolved skin, mean (SD) & $1.5(3.3)$ & $0.9(1.6)$ & ns \\
\hline CD138 ${ }^{+}$in clinically involved skin, mean (SD) & $3.5(1.5)$ & $3.8(2.9)$ & ns \\
\hline CD138 ${ }^{+}$in clinically uninvolved skin, mean (SD) & $1.7(1.8)$ & $2.2(2.1)$ & ns \\
\hline $\mathrm{CD}^{+}$in clinically involved skin, mean (SD) & $62.0(28.9)$ & $78.9(37.4)$ & ns \\
\hline $\mathrm{CD}^{+}{ }^{+}$in clinically uninvolved skin, mean (SD) & $43.7(40.2)$ & $47.2(33.9)$ & ns \\
\hline $\mathrm{CD} 8^{+}$in clinically involved skin, mean (SD) & $25.3(9.1)$ & $38.0(7.4)$ & ns \\
\hline $\mathrm{CD} 8^{+}$in clinically uninvolved skin, mean (SD) & $14.4(5.7)$ & $12.3(6.9)$ & ns \\
\hline Skin score after 6-month follow up, mean (SD) & $11.3(6.9)$ & $13.0(10.9)$ & ns \\
\hline Patients with decrease $>20 \%$ of skin score after 6 -month follow up ${ }^{b}$ & $11(91.7)$ & $3(18.7)$ & 0.01 \\
\hline Patients with worsening $>20 \%$ of skin score after 6 -month follow up & $0(0.0)$ & $7(56.3)$ & 0.01 \\
\hline Patients with CD2O + cells on skin biopsy & $0(0.0)$ & $7(77.8)$ & \\
\hline Patients without CD20+ cells on skin biopsy & $0(0.0)$ & $0(0.0)$ & \\
\hline
\end{tabular}

The values are indicated as the mean (SD) or number (percentage) according to the data distribution

SSC systemic sclerosis, ANA antinuclear antibodies, ACA anticentromere antibodies, anti-Scl-70 anti-topoisomerase antibodies, dSSC diffuse skin disease, ISSc limited skin disease, $n s$ not significant

aPresence of at least one CD20+ cell in involved or uninvolved skin biopsy

${ }^{b}$ In this subgroup, six patients had CD20+ cells in uninvolved skin and were treated with immunosuppressive drug, while none of the untreated patients had CD20+ cells $(p=0.002)$

cohort, about $40 \%$ of the patients had early SSc and we did not find any associations with disease duration or immunological characteristics.

Evidence of cellular skin infiltrate has been reported previously in another study [10], in which up to $50 \%$ of the biopsies had relevant dermal mononuclear infiltration, but low/mild infiltrate was found in the other specimens [10]. The patients with relevant infiltrate frequently presented with diffuse disease, shorter disease duration [10, $11]$ and a higher skin thickening score [10]. The majority of $\mathrm{T}$ cells present in the skin infiltrate were activated $\mathrm{T}$ lymphocytes $[10,11]$, suggesting that early $\mathrm{CD} 69^{+} \mathrm{T}$ cells may actively participate in cell-cell contact with fibroblasts to induce fibrosis in skin lesions [11]. In our study, all specimens had relevant mononuclear infiltration. This discrepancy between the results of the previous studies [10] and our data may be due to differences in disease duration or in the area of the body from which the specimens were taken. Furthermore, genome-wide gene expression profiling studies of SSc skin biopsies have demonstrated wide heterogeneity, which can be quantitatively measured by DNA microarrays [13, 38-40]. Four specific gene expression signatures in both lesional and non-lesional skin biopsies have been identified in scleroderma compared to healthy controls [39].

Interestingly, in our study, the inflammatory cell infiltration was also present in the clinical uninvolved cutaneous specimens, in which the skin apparently did not have any clinical signs of thickness and sclerosis. This finding is in agreement with the indistinguishable pattern of gene expression found in clinically affected and clinically unaffected tissue from patients with SSc, which was clearly different from the gene expression in healthy subjects [13]. Our immunohistochemical data indicated that in patients with SSc the skin, even when considered as clinically uninvolved, is affected by an inflammatory 
process, suggesting that pathological changes can be detected even before the onset of skin sclerosis. Gene expression profiling studies have confirmed an altered signature in unaffected skin in patients with systemic sclerosis $[13,16]$, highlighting the truly systemic inflammatory nature of the disease. Interestingly, in our study, the number of $\mathrm{CD} 68^{+}, \mathrm{CD}^{+}, \mathrm{CD} 20^{+}$and $\mathrm{CD} 138^{+}$cells was higher in involved skin than in uninvolved skin, suggesting a local role for these cells in accelerating the fibrogenic processes, that lead to clinical skin modifications. The role of macrophages in different target organs in patients with SSc has been recently demonstrated $[15,41]$ and confirmed in multiple cohorts with skin disease, showing that the gene expression of several activated macrophage markers are elevated in the skin in SSc [14]. Activated macrophages likely play a pivotal role in the pathogenesis of SSc by activating fibroblasts, but as these cells are plastic and readily modulated by the local tissue microenvironment, the cytokine milieu determined also by the presence of $\mathrm{B}$ and $\mathrm{T}$ lymphocytes, dendritic cells, endothelial cells and fibroblasts might play a role in the pathogenesis of the fibrotic process in the skin [41].

The role of T cells in SSc is already accepted [42]. In this regard, all SSc specimens examined in our study had significant $\mathrm{CD}^{+}$cell infiltrate mainly in clinically involved but also in uninvolved skin, supporting the concept that the dermal $\mathrm{T}$ lymphocytes play a key role in local pathogenic events in SSc by cytokine production and that lymphocyte/fibroblast interaction in the skin is important in the pathophysiology of SSc. However, the main clue to the specific importance of the immune cell infiltrates did arise from the longitudinal assessment of the course of the skin involvement. The mechanistic exploration of the pathogenic infiltrate still needs to be defined. The positive response to rituximab in a subgroup of patients with SSc, regardless of the baseline presence of B cell skin infiltrates, indirectly supports the notion that there might be a complex relationship among all mononuclear cells in determining clinical modification and fibrosis in scleroderma and probably the $\mathrm{T}$ and $\mathrm{B}$ cell crosstalk can have a role in promoting the fibrotic process.

Even though a recent analysis of DNA microarrays of cutaneous biopsies from patients with dSSc demonstrated higher expression of clusters of genes in $\mathrm{CD}^{+} \mathrm{O}^{+}$cells [13], in some immunohistochemical studies the $\mathrm{B}$ cells were rare or absent $[3,8-10]$. Recently, the analysis of B cell infiltrate performed in skin biopsies from patients treated with anti-CD20 therapy demonstrated improvement in the skin score and stabilization of FVC, DLCO and clinical symptoms [17-21, 23]. In our study, B cell infiltrate seems to be characteristic of the skin in scleroderma, in fact $\mathrm{CD} 20^{+}$and $\mathrm{CD} 138^{+}$cells were absent in all specimens from healthy subjects. B lymphocytes were detected in up to $61 \%$ of patients with SSc and the mean number of $\mathrm{CD} 20^{+}$and $\mathrm{CD} 138^{+}$cells was lower than the number of $\mathrm{CD}^{+}$and $\mathrm{CD}^{+} 8^{+}$cells. Fifty percent of these patients had $B$ cells both in involved and in uninvolved skin, while the other $50 \%$ had B cells only in involved skin, while plasma cells were present in all involved skin and in all but three samples of clinically uninvolved skin. The presence of plasma cells suggests that specific chemotaxis or local maturation of memory B cells had occurred. The wide variability in the identification of $B$ cells in skin biopsies in our study and in other studies could be related to the different cell signatures previously reported [39]. Certainly, the clinical effects seem not to depend upon the cell numbers found in the skin biopsy samples.

The great majority of patients with SSc who had $\mathrm{CD} 20^{+}$cells on skin biopsies had anti-Scl-70 Ab positivity or early disease or diffuse skin involvement. Patients with early disease had a greater number of $\mathrm{CD} 20^{+}$cells in involved skin compared with patients with longstanding disease, and the presence of $\mathrm{CD}_{2} \mathrm{O}^{+}$cells in uninvolved skin seems to be characteristic of patients with dSSc. Our sample size was not large enough to draw definite conclusions, but our data suggest that B cells are associated with the classical negative prognostic factor of scleroderma such as diffuse phenotype and antiscl-70 $\mathrm{Ab}$ positivity. Among the various immune cells, B cells appear to be the only ones linked to progression of skin involvement over time.

Albeit the number of patients enrolled in this study was limited, the worsening of skin involvement in the group of patients with $\mathrm{CD} 20^{+}$cells on skin biopsy after 6-month follow up suggests a possible prognostic value of $\mathrm{B}$ cell presence in the progression of skin involvement. No prognostic role was evident for plasma cells, suggesting that very likely they were already there, and that the arrival of the new B cells was the most important event for the diseased skin. The presence of B cells in the majority, but not in all patients, indicates an important, though not essential role for cutaneous B cells in more aggressive scleroderma disease, above all during the earliest phases when the inflammatory process and cell-cell interactions very likely play an essential role in the development of fibrosis over time. B cells in the skin may be involved in the initiation and expansion of the SSc inflammatory process. Of interest, even plasma cells were present either in the involved or the uninvolved skin and in 10 patients in this cohort on analysis of the peripheral blood $\mathrm{B}$ cell subsets, we found that the number of $\mathrm{CD} 20^{+}$and $\mathrm{CD} 138^{+}$cells in the skin specimens correlated directly with the percentage of circulating $\mathrm{CD} 27^{+} \mathrm{CD} 38^{+}$plasmablasts (unpublished data). Either resident and circulating $\mathrm{B}$ cells can determine, with their multiple functions as Ab-producing cells, antigen presenting cells and profibrotic and proinflammatory 
cytokine (IL-6, IL-4, transforming growth factor (TGF)- $\beta$ )secreting cells $[1,43]$, an autoimmune milieu that could be of great impact in the development of fibrosis. B cells directly stimulate fibroblasts by a direct contact-based mechanism [44] and a plethora of soluble factors present in the inflammatory skin condition contributes to the commitment of B cells in autoantibody-producing plasma cells, which, again, can directly stimulate fibroblasts.

The limited number of patients with scleroderma and of healthy controls in this study did not allow us to infer robust correlation with disease phenotype and organ involvement, but further studies on sequential biopsies after therapy could allow us to investigate temporal associations with different types of cell infiltrates, and to test correlation with the characteristics of inflammatory infiltrate with fibrotic involvement, such as the collagen score and myofibroblast score.

\section{Conclusions}

These results highlight that a subgroup of patients with SSc exhibit an imbalance in B cell infiltrate and that cutaneous mononuclear cells of the innate and adaptive immune system may play a role in mediating dermal fibrosis in different stages of scleroderma disease and in patients with diffuse skin involvement. Therapeutic approaches decreasing the numbers of cutaneous lymphocytes, in particular B cells, and/or interfering with their functions might prove useful in the management of cutaneous involvement in SSc from the earliest phases of the disease.

\section{Additional file}

Additional file 1: Table S1. Autoantibody characteristics according to scleroderma skin disease extension. (DOCX $14 \mathrm{~kb}$ )

\begin{abstract}
Abbreviations
Abs: Antibodies; ACA: Anti-centromere antibodies; ANA: Antinuclear antibodies; anti-Scl-70 Abs: Anti-topoisomerase antibodies; DLCO: diffusing capacity for carbon monoxide; dSSc: Diffuse systemic sclerosis;

ELISA: Enzyme-linked immunosorbent assay; ESR: Erythrocyte sedimentation rate; FVC: Forced vital capacity; GH: Global Health; $\mathrm{H}_{2} \mathrm{O}_{2}$ : Hydrogen peroxide; HAQ: Health Assessment Questionnaire; HRCT: High resolution computed tomography; IL: Interleukin; ISSc: Limited systemic sclerosis; LVEF: Left ventricular ejection fraction; mAb: monoclonal antibodies; PASP: Pulmonary artery systolic pressure; PFT: Pulmonary function test; RT: Room temperature; SD: Standard deviation; SSc: Systemic sclerosis; TBS: Tris-buffered saline
\end{abstract}

\section{Acknowledgements}

None.

Funding

The GILS supported the study.

Availability of data and materials

Please contact the author for data requests.

\section{Authors' contributions}

SB conceived and designed the study, collected clinical data and biopsies and analyzed and interpreted data, wrote the manuscript and gave final approval of the version to be published. CA designed the experiments, analyzed immunohistochemical results, participated in data analyses and in the writing of the manuscript, revised the manuscript and gave final approval of the version to be published. SA collected clinical data and biopsies, performed immunohistochemistry, interpreted data, revised the manuscript critically for important intellectual content and gave final approval of the version to be published. GL gave technical support and conceptual advice in immunohistochemistry, revised the manuscript critically and gave final approval of the version to be published. GP gave technical support and conceptual advice in immunohistochemistry, revised the manuscript critically and gave final approval of the version to be published. BT collected clinical data, analyzed data, revised the manuscript critically for important intellectual content, and gave final approval of the version to be published. GS provided a critical interpretation of the experimental data, revised the manuscript critically for important intellectual content and gave final approval of the version to be published. EG collected clinical data, analyzed data, critically revised the manuscript and gave final approval of the version to be published. GF conceived and designed the study, interpreted data, revised the manuscript critically for important intellectual content and gave final approval of the version to be published. All authors read and approved the final manuscript.

\section{Ethics approval and consent to participate}

This study was approved by our institutional ethics committee (Comitato Etico Università Cattolica del Sacro Cuore 1883/12), and study participants gave written informed consent.

\section{Consent for publication}

Not applicable.

\section{Competing interests}

The authors declare that they have no competing interests.

\section{Publisher's Note}

Springer Nature remains neutral with regard to jurisdictional claims in published maps and institutional affiliations.

\section{Author details}

${ }^{1}$ Unità Operativa Complessa di Reumatologia, Istituto di Reumatologia e Scienze Affini, Università Cattolica del Sacro Cuore, Rome, Italy. ${ }^{2}$ Fondazione Policlinico Universitario Agostino Gemelli, Via G. Moscati, 31-00168 Rome, Italy. ${ }^{3}$ Istituto di Istologia ed Embriologia, Università Cattolica del Sacro Cuore, Rome, Italy.

Received: 15 September 2017 Accepted: 15 March 2018

Published online: 18 April 2018

\section{References}

1. Gu YS, Kong J, Cheema GS, Keen CL, Wick G, Gershwin ME. The immunobiology of systemic sclerosis. Semin Arthritis Rheum. 2008:38:132-60.

2. Derk CT, Jimenez SA. Systemic sclerosis: current views of its pathogenesis. Autoimmun Rev. 2003:2:181-91.

3. Prescott R, Freemont A, Jones C, Hoyland J, Fielding P. Sequential dermal microvascular and perivascular changes in the development of scleroderma. J Pathol. 1992;166:255-63.

4. Nishioka K, Kobayashi Y, Katayama I, Takijiri C. Mast cells in diffuse scleroderma. Arch Dermatol. 1987;123:205-8.

5. Hawkins RA, Claman HN, Clark RAF, Steigerwald JC. Increased dermal mast cell populations in progressive systemic sclerosis: a link in chronic fibrosis? Ann Intern Med. 1985;102:182-6.

6. Fleischmajer R, Perlish JS, Reeves JRT. Cellular infiltrates in scleroderma skin. Arthritis Rheum. 1977;20:975-84.

7. Ishikawa O, Ishikawa H. Macrophages infiltration in the skin of patients with systemic sclerosis. J Rheumatol. 1992;19:1202-6.

8. Hussein MR, Hassan HI, Hofny ER, Elkholy M, Fatehy NA, Abd Elmoniem AE, et al. Alterations of mononuclear inflammatory cells, CD4/CD8+ cells, interleukin-1 $\beta$, and tumor necrosis factor-a in the bronchoalveolar lavage fluid, peripheral blood, and skin of patients with systemic sclerosis. J Clin Pathol. 2005;58:178-84.

9. Krailing BM, Maul G, Jimenez SA. Mononuclear cellular infiltrates in clinically involved skin from patients with systemic sclerosis of recent 
onset predominantly consist of monocytes/macrophages. Pathobiology. 1995;63:48-56.

10. Roumm A, Whiteside TL, Medseger T, Rodnan G. Lymphocytes in the skin of patients with progressive systemic sclerosis. Arthritis Rheum. 1984;27:645-53.

11. Kalogerou A, Gelou E, Mountantonakis S, Settas L, Zaforiou E, Sakkas L. Early activation in the skin from patients with systemic sclerosis. Ann Rheum Dis. 2005;64:1233-5.

12. Antiga E, Quaglino P, Bellandi S, Volpi W, Del Bianco E, Comessatti A, et al. Regulatory $T$ cells in the skin lesions and blood of patients with systemic sclerosis and morphoea. Br J Dermatol. 2010;162:1056-63.

13. Whitfield ML, Finlay DR, Murray JI, Troyanskaya OG, Chi JT, Pergamenschikov A, et al. Systemic and cell type-specific gene expression patterns in scleroderma skin. Proc Natl Acad Sci USA. 2003;100:12319-24.

14. Taroni JN, Greene CS, Martyanov V, Wood TA, Christmann RB, Farber HW, et al. A novel multinetwork approach reveals tissue-specific cellular modulators of fibrosis in systemic sclerosis Genome Med. 2017;9(1):27.

15. Assassi S, Swindell WR, Wu M, Tan FD, Khanna D, Furst DE, et al. Dissecting the heterogeneity of skin gene expression patterns in systemic sclerosis. Arthritis Rheumatol. 2015;67:3016-26.

16. Johnson ME, Pioli PA, Whitfield ML. Gene expression profiling offers insights into the role of innate immune signaling in SSc. Semin Immunopathol. 2015;37:501-9.

17. Lafyatis R, Kissin E, York M, Farina G, Viger K, Fritzler MJ, et al. B cell depletion with rituximab in patients with diffuse cutaneous systemic sclerosis. Arthritis Rheum. 2009;60:578-83.

18. Smith V, Van Praet JT, Vandooren B, Van der Cruyssen B, Naeyaert JM, Decuman $\mathrm{S}$, et al. Rituximab in diffuse cutaneous systemic sclerosis: an open-label clinical and histopathological study. Ann Rheum Dis. 2008;69: 193-7.

19. Bosello S, De Santis M, Lama G, Spanò C, Angelucci C, Tolusso B, et al. B cell depletion in diffuse progressive systemic sclerosis: safety, skin score modification and IL-6 modulation in a thirty-six months follow-up open label trial. Arthritis Res Ther. 2010;12:R 54.

20. Daoussis D, Liossis SN, Tsamandas AC, Kalogeropoulou C, Kazantzi A, Sirinian C, et al. Experience with rituximab in scleroderma: results from a 1-year, proof-ofprinciple study. Rheumatology. 2010:49:271-80.

21. Bosello SL, De Luca G, Rucco M, Berardi G, Falcione M, Danza FM, et al. G. Long-term efficacy of B cell depletion therapy on lung and skin involvement in diffuse systemic sclerosis. Semin Arthritis Rheum. 2015; 44:428-36.

22. Bosello S, De Luca G, Tolusso B, Lama G, Angelucci C, Sica G, et al. B cells in systemic sclerosis: a possible target for therapy. Autoimmun Rev. 2011;10: 624-30.

23. Jordan S, Distler JH, Maurer B, Huscher D, van Laar JM, Allanore Y, et al. Effects and safety of rituximab in systemic sclerosis: an analysis from the European Scleroderma Trial and Research (EUSTAR) group. Ann Rheum Dis. 2015:74:1188-94.

24. Okano Y. Antinuclear antibody in systemic sclerosis (scleroderma). Rheum Dis Clin N Am. 1996;22:709-35.

25. Famularo G, Giacomelli R, Alesse E, Cifone MG, Morrone S, Boirivant M, et al. Polyclonal B lymphocyte activation in progressive systemic sclerosis. J Clin Lab Immunol. 1989;29:59-63.

26. Sato S, Fujimoto M, Hasegawa M, Takehara K. Altered blood B lymphocyte homeostasis in systemic sclerosis: expanded naive B cells and diminished but activated memory B cells. Arthritis Rheum. 2004;50:1918-27.

27. Sato S, Hasegawa M, Fujimoto M, Tedder TF, Takehara K. Quantitative genetic variation in CD19 expression correlates with autoimmunity. J Immunol. 2000;165:6635-43.

28. Subcommittee for Scleroderma Criteria of the American Rheumatism Association Diagnostic and Therapeutic Criteria Committee. Preliminary criteria for the classification of systemic sclerosis (scleroderma). Arthritis Rheum. 1980;23:581-90.

29. van den Hoogen F, Khanna D, Fransen J, Johnson SR, Baron M, Tyndall A, et al. 2013 classification criteria for systemic sclerosis: an American college of rheumatology/European league against rheumatism collaborative initiative. Ann Rheum Dis. 2013;72:1747-55.

30. LeRoy EC, Black C, Fleischmajer R, Jablonska S, Krieg T, Medsger TA Jr, et al. Scleroderma (systemic sclerosis): classification, subset and pathogenesis. J Rheumatol. 1988;15:202-5.

31. Valentini G, D'Angelo S, Della Rossa A, Bencivelli W, Bombardieri S European Scleroderma Study Group to define disease activity criteria for systemic sclerosis: IV: assessment of skin thickening by modified Rodnan skin score. Ann Rheum Dis. 2003;62:904-5.

32. Czirják L, Nagy Z, Aringer M, Riemekasten G, Matucci-Cerinic M, Furst DE, EUSTAR. The EUSTAR model for teaching and implementing the modified Rodnan skin score in systemic sclerosis. Ann Rheum Dis. 2007;66:966-9.

33. Clements $P$, Lachenbruch $P$, Siebold J, White B, Weiner S, Martin R, et al. Inter- and intraobserver variability of total skin thickness score (modified Rodnan TSS) in systemic sclerosis. J Rheumatol. 1995;22:1281-5.

34. Valentini G, Silman AJ, Veale D. Assessment of disease activity. Clin Exp Rheumatol. 2003;21(Suppl 29):S39-41.

35. Medsger TA Jr, Bombardieri S, Czirjak L, Scorza R, Della Rossa A, Bencivelli W. Assessment of disease severity and prognosis. Clin Exp Rheumatol. 2003; 21(Suppl 29):S42-6.

36. De Santis M, Bosello S, La Torre G, Capuano A, Tolusso B, Pagliari G, et al. Functional, radiological and biological markers of alveolitis and infections of the lower respiratory tract in patients with systemic sclerosis. Respir Res. 2005;6:96-106.

37. Alivernini S, Kurowska-Stolarska M, Tolusso B, Benvenuto R, Elmesmari A Canestri S, et al. microRNA-155 influences B-cell function in rheumatoid arthritis. Nat Commun. 2016;7:12970.

38. Gardner H, Shearstone JR, Bandaru R, Crowell T, Lynes M, Trojanowska M, et al. Gene profiling of scleroderma skin reveals robust signatures of disease that are imperfectly reflected in the transcript profiles of explanted fibroblasts. Arthritis Rheum. 2006;54:1961-73.

39. Milano A, Pendergrass SA, Sargent JL, George LK, McCalmont TH, Connolly MK, et al. Molecular subsets in the gene expression signatures of scleroderma skin. PLoS One. 2008;3:e2696.

40. Pendergrass SA, Lemaire R, Francis IP, Mahoney JM, Lafyatis R, Whitfield ML. Intrinsic gene expression subsets of diffuse cutaneous systemic sclerosis are stable in serial skin biopsies. J Invest Dermatol. 2012;132:1363-73.

41. Chia JJ, Lu TT. Update on macrophages and innate immunity in scleroderma. Curr Opin Rheumatol. 2015;27:530-6.

42. Sakkas LI, Platsoucas CD. Is systemic sclerosis an antigen-driven T cell disease. Arthritis Rheum. 2004;50:1721-3.

43. Alivernini S, De Santis M, Tolusso B, Mannocci A, Bosello SL, Peluso G, et al. Skin ulcers in systemic sclerosis: determinants of presence and predictive factors of healing. J Am Acad Dermatol. 2009;60:426-35.

44. François A, Chatelus E, Wachsmann D, Sibilia J, Bahram S, Alsaleh G, et al. B lymphocytes and B-cell activating factor promote collagen an profibrotic markers expression by dermal fibroblasts in systemic sclerosis. Arthritis Res Ther. 2013;15:R168.

\section{Submit your next manuscript to BioMed Central and we will help you at every step:}

- We accept pre-submission inquiries

- Our selector tool helps you to find the most relevant journal

- We provide round the clock customer support

- Convenient online submission

- Thorough peer review

- Inclusion in PubMed and all major indexing services

- Maximum visibility for your research

Submit your manuscript at www.biomedcentral.com/submit
Biomed Central 